\title{
Solubility of a pharmacological intermediate drug Isatin in different solvents at various temperatures
}

\author{
Shipra Baluja*, Rahul Bhalodia, Mehul Bhatt, Nayan Vekariya, Ravi Gajera \\ Physical Chemical Laboratory, Department of Chemistry, Saurashtra University, \\ Rajkot 360 005, India \\ *E-mail address: shipra_baluja@rediffmail.com
}

\begin{abstract}
The solubility of isatin in different solvents was studied by a gravimetrical method from ( 298.15 to 318.15$) \mathrm{K}$ under atmospheric pressure and the solubility data were correlated against temperature. The solvents selected for the present study are: water, methanol, ethanol, 1-butanol, dichloromethane, dichloroethane, chloroform and carbon tetra chloride. Among chlorinated solvents, solubility is observed to be maximum in 1,2-dichloroethane and minimum in dichloromethane whereas in alcohols, maximum solubility is observed in methanol. In water, solubility is found to be minimum. Further, some thermodynamic parameters such as Gibb's energy $\left(\Delta G_{s o l}\right)$, heat of solution $\left(\Delta H_{s o l}\right)$ and entropy of solution $\left(\Delta S_{\text {sol }}\right)$ have also been evaluated.
\end{abstract}

Keywords: Isatin; solubility; Thermodynamic parameters

\section{INTRODUCTION}

Isatin or $1 \mathrm{H}$-indole-2,3-dione is an indole derivative which is found in many plants. It is a yellow to red needle crystalline solid which has arose great attention in recent years due to their wide variety of biological activities and pharmacological studies as fungicides, ${ }^{1}$ insecticides $^{2}$, anticancer ${ }^{3}$, anticonvulsant ${ }^{4}$, anti $\mathrm{HIV}^{5}$, anti protozoal ${ }^{6}$, enzymatic ${ }^{7}$, antimicrobial $^{8}$, antifungal ${ }^{9}$, anti-inflammatory ${ }^{10}$, anticonvulsant ${ }^{11}$ and cytotoxic $^{12}$ and antioxidant $^{13}$ etc. Moreover, isatins are the synthetic precursors of some biologically important compounds ${ }^{14,15}$.

Because of the continuing interest about isatin and its derivatives ${ }^{16-19}$, the present work was undertaken to test the solubility of isatin in different solvents at different temperatures and as a result, to evaluate different thermodynamic parameters. Further, various thermodynamic parameters have been evaluated from these solubility data. The solubility data of isatin may be used in the various fields of chemistry and pharmaceutical industry.

This work is the continuation of our systematic study of solubilities of drug in different solvents. In this paper the solubility of isatin in different solvents such as water, methanol, ethanol, 1-butanol, dichloromethane, dichloroethane, chloroform and carbon tetrachloride have been determined ${ }^{26}$. 


\section{EXPERIMENTAL}

Isatin, with a mass purity of $99.7 \%$, was purchased from (Loba Chemicals, Mumbai). All the solvents selected for the present study were analytical grade reagents, which were purified by fractional distillation. Their purities were checked by SHIMADZU GC-MS (Model No QP-2010) and were found to be greater than $99.70 \%$.

The drug was recrystallized and its melting point was determined by DSC. The observed value was found to be $472 \mathrm{~K}$ which is in good agreement with the reported value ${ }^{20}$ (473 K).

\section{1. Description of experiment}

The solubilities were measured by a gravimetric method ${ }^{21}$. For each measurement, an excess mass of isatin was added to a known mass of solvent. Then, the equilibrium cell was heated to a constant temperature $\left( \pm 0.1{ }^{\circ} \mathrm{C}\right)$ with continuous stirring. After, 3 hours, temperature of water was constant and was recorded. The stirring was stopped and the solution was kept still for $2 \mathrm{hrs}$. A portion of this solution was filtered and by a preheated injector, $2 \mathrm{ml}$ of this clear solution was taken in another weighted measuring vial $\left(m_{0}\right)$. The vial was quickly and tightly closed and weighted $\left(m_{1}\right)$ to determine the mass of the sample $\left(m_{1^{-}} m_{0}\right)$. Then, the vial was covered with a piece of filter paper to prevent dust contamination. Then, the vial was placed in at room temperature to evaporate the solvent.

After the solvent in the vial had completely evaporated, the vial was dried and reweighed $\left(m_{2}\right)$ to determine the mass of the constant residue solid $\left(m_{2^{-}} m_{0}\right)$. All the weights were taken using an electronic balance (Mettler Toledo AB204-S, Switzerland) with an accuracy of $\pm 0.0001 \mathrm{~g}$. Thus, the solid concentration of the sample solution of mole fraction, $x$, could be determined from equation 1 .

$$
x=\frac{\left(m_{2}-m_{0}\right) / M_{1}}{\left(m_{2}-m_{0}\right) / M_{1}+\left(m_{1}-m_{2}\right) / M_{2}}
$$

where $M_{1}$ is the molar mass of isatin and $M_{2}$ is the molar mass of the solvent.

At each temperature, the measurement was repeated three times and an average value is given in Table 1 .

Table 1. Observed mole fraction solubilities $(x)$, calculated mole fraction solubilities $\left(x_{c i}\right)$ and relative deviation $(R D)$ of Isatin in different solvents.

\begin{tabular}{|c|c|c|c|}
\hline T/K & $\boldsymbol{x}$ & $\boldsymbol{x}_{\boldsymbol{c} i}$ & 100 RD \\
\hline \multicolumn{3}{|c|}{ Dichloromethane } \\
\hline 298.15 & $0.0030 \pm 0.001$ & 0.0031 & 0.21 \\
\hline 300.15 & $0.0033 \pm 0.006$ & 0.0032 & -0.34 \\
\hline 303.15 & $0.0037 \pm 0.005$ & 0.0035 & -1.00 \\
\hline 305.15 & $0.0039 \pm 0.010$ & 0.0037 & -1.34 \\
\hline
\end{tabular}




\begin{tabular}{|c|c|c|c|}
\hline 308.15 & $0.0043 \pm 0.009$ & 0.0039 & -1.71 \\
\hline 310.15 & $0.0045 \pm 0.008$ & 0.0041 & -1.36 \\
\hline 313.15 & $0.0047 \pm 0.006$ & 0.0045 & -0.80 \\
\hline 315.15 & $0.0048 \pm 0.012$ & 0.0047 & -0.41 \\
\hline 318.15 & $0.0050 \pm 0.015$ & 0.0051 & 0.23 \\
\hline \multicolumn{4}{|c|}{ 1,2-dichloroethane } \\
\hline 298.15 & $0.0540 \pm 0.003$ & 0.0547 & 0.39 \\
\hline 300.15 & $0.0562 \pm 0.004$ & 0.0561 & -0.05 \\
\hline 303.15 & $0.0606 \pm 0.007$ & 0.0585 & -1.30 \\
\hline 305.15 & $0.0636 \pm 0.005$ & 0.0601 & -2.09 \\
\hline 308.15 & $0.0661 \pm 0.003$ & 0.0626 & -2.05 \\
\hline 310.15 & $0.0674 \pm 0.013$ & 0.0643 & -1.79 \\
\hline 313.15 & $0.0690 \pm 0.011$ & 0.0669 & -1.16 \\
\hline 315.15 & $0.0698 \pm 0.002$ & 0.0687 & -0.59 \\
\hline 318.15 & $0.0711 \pm 0.008$ & 0.0716 & 0.24 \\
\hline \multicolumn{4}{|c|}{ Chloroform } \\
\hline 298.15 & $0.0306 \pm 0.015$ & 0.0306 & 0.01 \\
\hline 300.15 & $0.0312 \pm 0.001$ & 0.0311 & -0.12 \\
\hline 303.15 & $0.0317 \pm 0.006$ & 0.0319 & 0.10 \\
\hline 305.15 & $0.0321 \pm 0.002$ & 0.0324 & 0.26 \\
\hline 308.15 & $0.0326 \pm 0.003$ & 0.0332 & 0.50 \\
\hline 310.15 & $0.0334 \pm 0.002$ & 0.0337 & 0.24 \\
\hline 313.15 & $0.0347 \pm 0.013$ & 0.0345 & -0.13 \\
\hline 315.15 & $0.0355 \pm 0.005$ & 0.0351 & -0.36 \\
\hline 318.15 & $0.0357 \pm 0.003$ & 0.0359 & 0.16 \\
\hline \multicolumn{4}{|c|}{ Carbon tetrachloride } \\
\hline 298.15 & $0.0235 \pm 0.016$ & 0.0230 & -0.61 \\
\hline 300.15 & $0.0258 \pm 0.012$ & 0.0257 & -0.20 \\
\hline
\end{tabular}




\begin{tabular}{|c|c|c|c|}
\hline 303.15 & $0.0293 \pm 0.015$ & 0.0302 & 0.86 \\
\hline 305.15 & $0.0316 \pm 0.013$ & 0.0337 & 1.84 \\
\hline 308.15 & $0.0351 \pm 0.015$ & 0.0397 & 3.68 \\
\hline 310.15 & $0.0419 \pm 0.018$ & 0.0443 & 1.76 \\
\hline 313.15 & $0.0521 \pm 0.011$ & 0.0522 & 0.07 \\
\hline 315.15 & $0.0589 \pm 0.011$ & 0.0583 & -0.39 \\
\hline 318.15 & $0.0691 \pm 0.010$ & 0.0687 & -0.25 \\
\hline \multicolumn{4}{|c|}{ Methanol } \\
\hline 298.15 & $0.0057 \pm 0.0005$ & 0.0057 & -0.3425 \\
\hline 300.15 & $0.0058 \pm 0.0002$ & 0.0058 & 0.1459 \\
\hline 303.15 & $0.0058 \pm 0.0004$ & 0.0059 & 0.2903 \\
\hline 305.15 & $0.0059 \pm 0.0003$ & 0.0060 & 0.0067 \\
\hline 308.15 & $0.0060 \pm 0.0002$ & 0.0061 & -0.9809 \\
\hline 310.15 & $0.0061 \pm 0.0002$ & 0.0062 & -0.2050 \\
\hline 313.15 & $0.0064 \pm 0.0001$ & 0.0064 & 0.3667 \\
\hline 315.15 & $0.0065 \pm 0.0002$ & 0.0065 & 0.2746 \\
\hline 318.15 & $0.0067 \pm 0.0001$ & 0.0068 & -0.3899 \\
\hline \multicolumn{4}{|c|}{ Ethanol } \\
\hline 298.15 & $0.0040 \pm 0.0002$ & 0.0041 & 0.4431 \\
\hline 300.15 & $0.0043 \pm 0.0001$ & 0.0043 & 1.5018 \\
\hline 303.15 & $0.0045 \pm 0.0005$ & 0.0046 & -1.5929 \\
\hline 305.15 & $0.0048 \pm 0.0004$ & 0.0048 & 0.1470 \\
\hline 308.15 & $0.0050 \pm 0.0007$ & 0.0051 & -1.8806 \\
\hline 310.15 & $0.0053 \pm 0.0006$ & 0.0054 & -0.9412 \\
\hline 313.15 & $0.0057 \pm 0.0004$ & 0.0057 & 0.1131 \\
\hline 315.15 & $0.0059 \pm 0.0002$ & 0.0060 & 0.5238 \\
\hline 318.15 & $0.0064 \pm 0.0004$ & 0.0064 & 0.7780 \\
\hline \multicolumn{4}{|c|}{ 1-Butanol } \\
\hline
\end{tabular}




\begin{tabular}{|c|c|c|c|}
\hline 298.15 & $0.0049 \pm 0.0001$ & 0.0049 & -0.1593 \\
\hline 300.15 & $0.0053 \pm 0.0002$ & 0.0054 & -0.2327 \\
\hline 303.15 & $0.0060 \pm 0.0001$ & 0.0061 & -0.2313 \\
\hline 305.15 & $0.0065 \pm 0.0004$ & 0.0065 & 0.0975 \\
\hline 308.15 & $0.0072 \pm 0.0005$ & 0.0071 & 1.0539 \\
\hline 310.15 & $0.0074 \pm 0.0003$ & 0.0075 & -0.2152 \\
\hline 313.15 & $0.0079 \pm 0.0004$ & 0.0080 & -1.0073 \\
\hline 315.15 & $0.0081 \pm 0.0001$ & 0.0083 & -0.7963 \\
\hline 318.15 & $0.008 \pm 0.0001$ & 0.0085 & 0.7016 \\
\hline \multicolumn{4}{|c|}{ Water } \\
\hline 298.15 & $5.1384 \mathrm{E}-05 \pm 0.0021 \mathrm{E}-05$ & $5.2410 \mathrm{E}-05$ & -1.9955 \\
\hline 300.15 & $5.8717 \mathrm{E}-05 \pm 0.0011 \mathrm{E}-05$ & 5.8017E-05 & 1.1932 \\
\hline 303.15 & $6.8491 \mathrm{E}-05 \pm 0.0057 \mathrm{E}-05$ & $6.7124 \mathrm{E}-05$ & 1.9955 \\
\hline 305.15 & $7.3372 \mathrm{E}-05 \pm 0.0060 \mathrm{E}-05$ & $7.3658 \mathrm{E}-05$ & -0.3895 \\
\hline 308.15 & $8.3138 \mathrm{E}-05 \pm 0.0043 \mathrm{E}-05$ & 8.4142E-05 & -1.2077 \\
\hline 310.15 & $9.0458 \mathrm{E}-05 \pm 0.0044 \mathrm{E}-05$ & $9.1575 \mathrm{E}-05$ & -1.2340 \\
\hline 313.15 & $10.2657 \mathrm{E}-05 \pm 0.0020 \mathrm{E}-05$ & $10.336 \mathrm{E}-05$ & -0.6857 \\
\hline 315.15 & 11.2417E-05 $\pm 0.0031 \mathrm{E}-05$ & 11.162E-05 & 0.7082 \\
\hline 318.15 & $12.4604 \mathrm{E}-05 \pm 0.0034 \mathrm{E}-05$ & 12.457E-05 & 0.0286 \\
\hline
\end{tabular}

Table 2. Dielectric constant and Dipole moment of solvents.

\begin{tabular}{|c|c|c|}
\hline Solvent & Dielectric Constant & Dipole Moment \\
\hline 1,2-Dichloroethane & 10.36 & 1.20 \\
\hline Dichloromethane & 9.08 & 1.60 \\
\hline Chloroform & 4.81 & 1.01 \\
\hline Carbon tetrachloride & 2.24 & 0.00 \\
\hline Methanol & 33.00 & 1.70 \\
\hline Ethanol & 24.3 & 1.69 \\
\hline
\end{tabular}




\begin{tabular}{|c|c|c|}
\hline 1-Butanol & 17.8 & 1.66 \\
\hline Water & 78.8 & 1.85 \\
\hline
\end{tabular}

Table 3. Constants A, B and C of eq (2) and root mean square deviation (RMSD) of isatin in different solvents.

\begin{tabular}{|c|c|c|c|c|}
\hline Solvents & $\boldsymbol{A}$ & $\boldsymbol{B}$ & $\boldsymbol{C}$ & $\mathbf{1 0}^{-5} \mathbf{R M S D}$ \\
\hline dichloromethane & 869.25 & -42785.87 & -130.47 & 0.0036 \\
\hline 1,2-dichloroethane & 470.55 & -22012.18 & -66.87 & 4.0500 \\
\hline chloroform & -93.65 & -13312.23 & -39.91 & 0.0069 \\
\hline carbon tetrachloride & -693.62 & 13915.78 & -63.99 & 2.9265 \\
\hline Methanol & -440.85 & 19273.15 & 65.12 & 0.7891 \\
\hline Ethanol & -2.27 & -1930.97 & 0.5691 & 5.9600 \\
\hline 1-Butanol & 1103.4604 & -52942.48 & -163.44 & 4.9312 \\
\hline Water & 342.41 & -19593.67 & -50.292 & 0.4741 \\
\hline
\end{tabular}

Table 4. Thermodynamic parameters Gibb's energy $\left(\Delta G_{s o l}\right)$, heat of solution $\left(\Delta H_{s o l}\right)$ and entropy of solution $\left(\Delta S_{\text {sol }}\right)$ of dissolution of Isatin in various solvents.

\begin{tabular}{|c|c|c|c|}
\hline Solvents & $\boldsymbol{\Delta} \mathbf{G} / \mathbf{k J} \cdot \mathbf{m o l}^{\mathbf{1}}$ & $\Delta \mathbf{H} / \mathbf{k J} \cdot \mathbf{m o l}^{-\mathbf{1}}$ & $\Delta \mathbf{S} / \mathbf{J} \cdot \mathbf{m o l}^{-\mathbf{1}} \mathbf{K}^{\mathbf{1}}$ \\
\hline dichloromethane & 14.09 & 19.57 & 17.83 \\
\hline 1,2-dichloroethane & 7.04 & 10.90 & 12.54 \\
\hline chloroform & 8.73 & 6.52 & -7.17 \\
\hline carbon tetrachloride & 8.35 & 43.08 & 112.82 \\
\hline Methanol & 13.0359 & 6.4184 & -21.4868 \\
\hline Ethanol & 13.5137 & 17.5101 & 12.9759 \\
\hline 1-Butanol & 12.7609 & 21.9190 & 29.7358 \\
\hline Water & 24.0763 & 34.2013 & 32.8755 \\
\hline
\end{tabular}




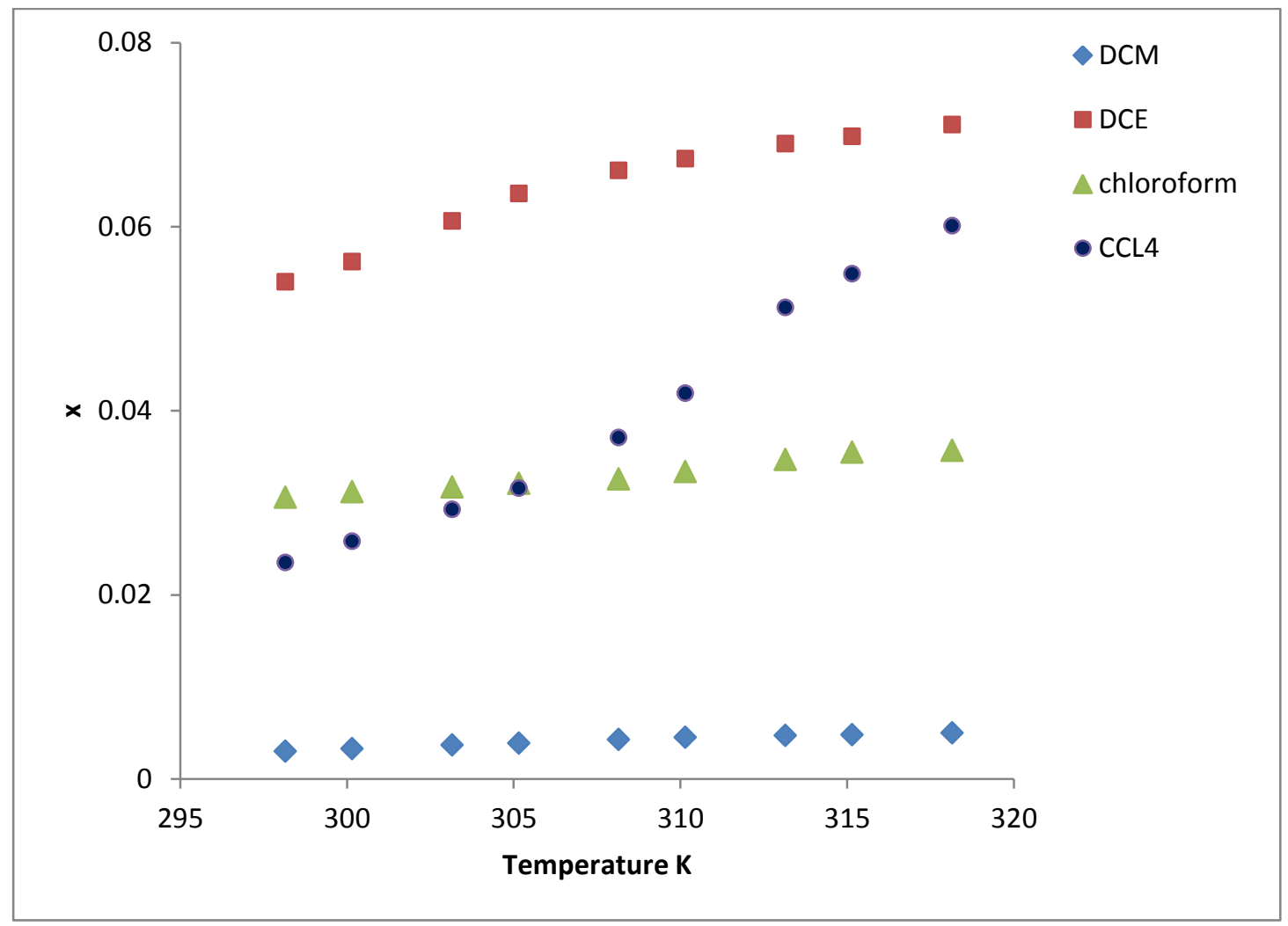

Figure 2(a). Variation of mole fraction solubilities $(x)$ with temperature in different solvents.

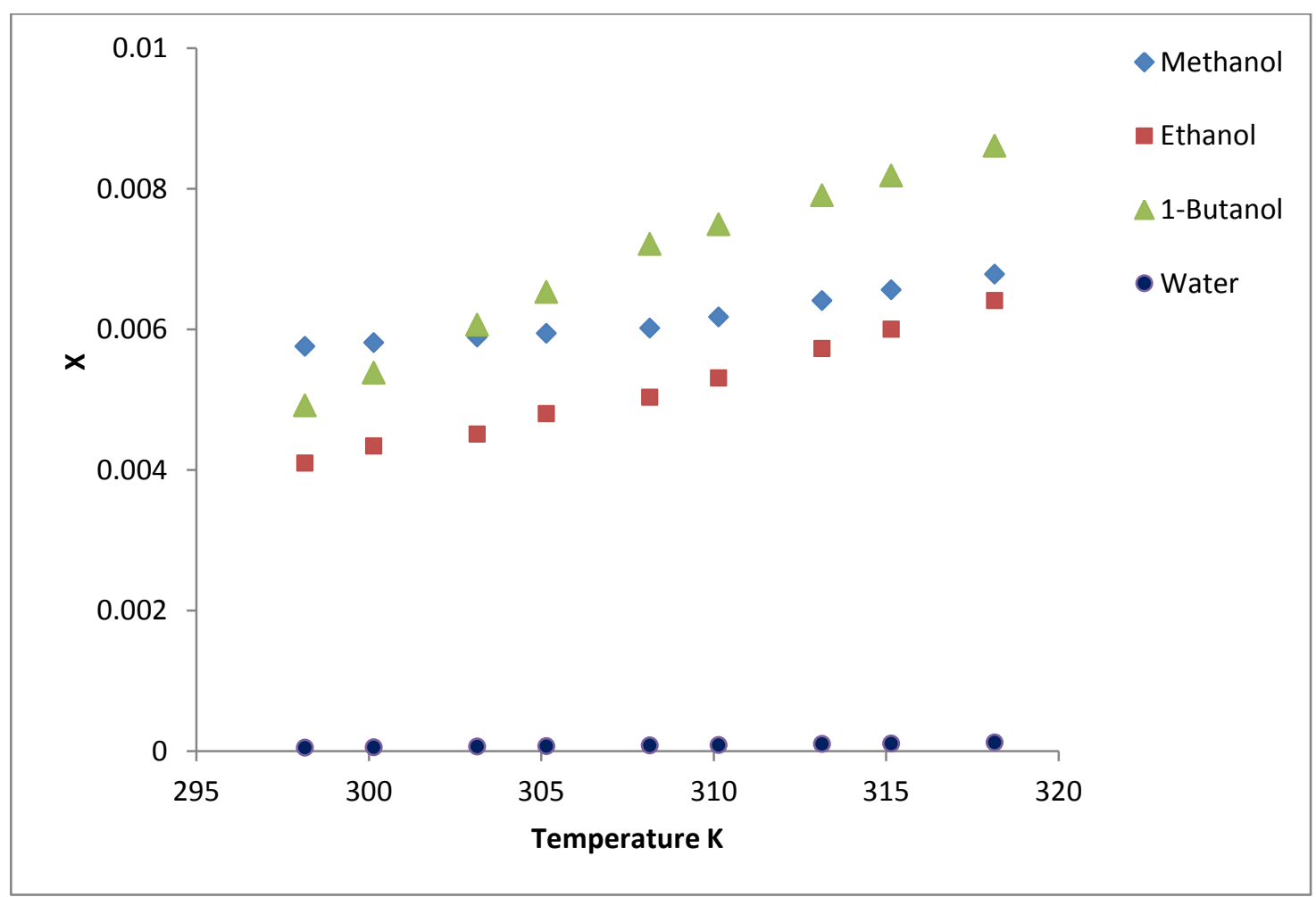

Figure 2(b). Variation of mole fraction solubilities $(x)$ with temperature in different solvents. 


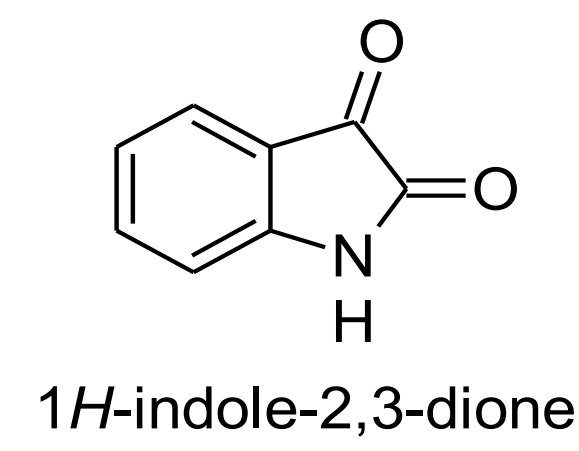

Figure 1. Structure of Isatin.

\section{RESULTS AND DISCUSSION}

The mole fraction solubilities $x$ of isatin in studied solvents at different temperatures (298.15 to 318.15 ) are summarized in Table 1 . It is evident from Table 1 that among chlorinated solvents, solubility is minimum in dichloromethane and maximum in 1,2dichloroethane whereas in alcohols, maximum solubility is observed in methanol. In water, solubility is found to be minimum.

Table 2 shows dielectric constants and dipole moments of the studied solvents. It is well known fact that solubility is affected by dielectric constant and dipole moment of the solvents. Among alcohols and water, dielectric constant and dipole moments is maximum for water and minimum for 1-butanol. But, it is observed that solubility is minimum in water and maximum for 1-butanol. If water is excluded from alcohols then maximum dielectric constant and dipole moments are for methanol where solubility is higher at lower temperature but at higher temperatures, solubility is found to be greater for 1-butanol. This may be due to disruption of structure due to bulky 1-butanol as compared to other two alcohols.

Among chlorinated solvents, dielectric constant and dipole moments is maximum for 1,2-dichloroethane and minimum for carbon tetrachloride. The maximum solubility in 1,2dichloroethane can be explained due to its high dielectric constant. However, minimum solubility is observed in dichloromethane which is having dielectric constant greater than chloroform and carbon tetra chloride. When dipole moments of the four solvents are compared, it is observed that dipole moment is maximum for dichloromethane which may be the reason for less solubility in this solvent. Again, in this case also, bulky 1,2-dichloroethane may cause greater solubility as compared to other chlorinated solvents.

The variation of solubility with temperature is also shown in Figure 2. It is observed that solubility increases with increase of temperature. As shown in Figure 2, the mole fraction solubility $x$ of isatin was correlated as a function of temperature. The temperature dependence of the drug solubility in solvents is described by the modified Apelblat equation ${ }^{22}$

$$
\ln (x)=A+B /(T / K)+C \ln (T / K)
$$

where $x$ is the mole fraction solubility of isatin, $T$ is the absolute temperature and $A, B$ and $C$ are the parameters. 
The values of these parameters are given in Table 3. The calculated solubilities $x_{c i}$ are also reported in Table 1. The experimental solubility of isatin in the studied solvents was compared with calculated solubility $\left(x_{c i}\right)$.

Further, root-mean-square deviations (RMSD), calculated by equations 3 is listed in Table 2.

$$
R M S D=\left[\sum_{i=1}^{N} \frac{\left(x_{c i}-x_{i}\right)^{2}}{N-1}\right]^{1 / 2}
$$

where $N$ is the number of experimental points and $x_{c i}$ is the solubility calculated by equation 2.

The relative deviations (RD) between the experimental and calculated values of solubilities are also calculated by equation 4 and are given in Table 1.

$$
\text { Relative Deviation }=\left(\frac{x-x_{c i}}{x}\right)
$$

The heat of solution $\left(\Delta H_{\text {sol }}\right)$ was calculated by modified van't Hoff equation ${ }^{23,24}$ :

$$
\frac{\partial \ln x}{\partial\left(1 / T-1 / T_{h m}\right)_{P}}=-\frac{\Delta H_{s o l}}{R}
$$

where $\mathrm{T}$ is the experimental temperature and $\mathrm{R}$ is perfect gas constant $\left(8.314 \mathrm{~J} . \mathrm{mole}^{-1} \cdot \mathrm{K}^{-1}\right)$. $T_{h m}$ is the mean harmonic temperature which is given as

$$
T_{h m}=\frac{n}{\sum_{i}^{n}(1 / T)}
$$

where $\mathrm{n}$ is the number of experimental temperatures ${ }^{17}$. In the present case, the $T_{h m}$ value obtained is only $307.79 \mathrm{~K}$. The slope of the plot of $\ln x$ versus $(1 / T-1 / 307.79)$ gives the value of $\Delta H_{\text {sol }}$.

The Gibbs energy change for the solubility process was then evaluated from the following relation ${ }^{23}$ :

$$
\Delta G_{\text {sol }}=-R T \cdot \text { intercept }
$$

Using these evaluated $\Delta H_{\text {sol }}$ and $\Delta G_{\text {sol }}$ values, the entropy of solution $\Delta S_{\text {sol }}$ were obtained from equation ${ }^{23,24}$ : 


$$
\Delta S_{s o l}=\frac{\Delta H_{s o l}-\Delta G_{s o l}}{T_{h m}}
$$

All these thermodynamic parameters are given in Table 4.

It is evident from Table 4 that for all the solvents $\Delta G_{s o l}$ and $\Delta S_{\text {sol }}$ values are positive. When stronger bonds are broken and weaker bonds are formed, energy is consumed. So, $\Delta H_{\text {sol }}$ becomes positive ${ }^{24}$. This indicates endothermic dissolution of compounds where the enthalpy term contributes to an unfavorable positive value of $\Delta G_{s o l}$. Thus, positive value of $\Delta G_{s o l}$ indicates that the dissolution process is not spontaneous ${ }^{16}$. The positive $\Delta S_{\text {sol }}$ for dichloromethane, 1,2-dichloroethane and carbon tetrachloride confirms the complex formation. However negative $\Delta S_{\text {sol }}$ values in chloroform may due to absence of complex formation $^{25}$.

\section{CONCLUSION}

In alcohols, maximum solubility is observed in 1-Butanol whereas in chloriated solvents, it is maximum in 1,2-dichloroethane. Further, solubility increases with temperature. The dissolution process is not spontaneous and is endothermic.

\section{Acknowledgement} facilities.

Authors are thankful to Head of Chemistry Department for providing necessary

\section{References}

[1] V. K. Pandey, A. Dwivedi, O. P. Pandey, S. K. Sengupta, Journal of Agricultural and Food Chemistry 56 (2008) 10779-10784.

[2] P. Pakravan, S. Kashanian, M. M. Khodaei, F. J. Harding, Pharmacol Reports 65 (2013) 313-335.

[3] V. R. Solomon. C. Lee, H. Hu, Bioorganic and Medicinal Chemistry 17 (2009) 7585-7592.

[4] S. N. Pandeya, S. Smitha, M. Jyoti, Acta Pharmaceutica 55 (2005) 27-46.

[5] S. N. Pandeya, D. Sriram, G. Nath, E. De Clercq, European Journal of Medicinal Chemistry 35 (2000) 249-255.

[6] R. S. Varma, I. A. Khan, Polish Journal of Pharmacology and Pharmacy 29 (1977) 549-554.

[7] S. E. Sarciron, P. Audin, I. Delebre, C. Gabrion, A. F. Petavy, J. Paris, Journal of Pharmaceutical Sciences 82 (1993) 605-609.

[8] Gangarapu Kiran, Manda Sarangapani, Thumma Gouthami, Anreddy Rama Narsimha Reddy, Toxicological and Environmental Chemistry 95 (2013) 367-378. 
[9] Aanandhi M. Vijey, George Shiny, V. Vaidhyalingam, ARKIVOC xi (2008) 187-194.

[10] P. Panneerselvam, R. S. Reddy, K. Murali, N. R. Kumar, Der Pharma Chemica 2 (2010) 28-37.

[11] Vinit Raj, International Journal of Current Pharmaceutical Research 4 (2012) 1-9.

[12] M. Cândido-Bacani Pde, M. P. Mori, T. R. Calvo, W. Vilegas, E. A. Varanda, I. M. Cólus, Journal of Toxicological Environmental Health A. 76 (2013) 354-362.

[13] A. Andreani, S. Burnelli, M. Granaiola, A. Leoni, Europian Journal of Medicinal Chemistry 45 (2010) 1374-1378.

[14] Rahul R. Tripathi, Ratnamala P. Sonawane, International Letters of Chemistry, Physics and Astronomy 10(2) (2013) 119-125.

[15] V. J. Ram, A. A. Raj, R. Ragunathan, R. Raman, Archives of Pharmacology 108 (1980) 313-318.

[16] N. Sin, B. L. Venables, K. D. Combrink, H. B. Gulgeze, K. L. Yu, R. L. Civiello, Bioorganic and Medicinal Chemistry 19 (2009) 4857-4862.

[17] Bhanupriya Bhrigua, Devender Pathaka, Nadeem Siddiquib, M. Shamsher Alamb, Waquar Ahsanb, International Journal of Pharmaceutical Sciences and Drug Research 2 (2010) 229-235.

[18] Dhruv Kumar Chaudhary, Shamim Ahmad, Supriya Maitya, M. Shamsher Alama, Der Pharmacia Lettre 5 (2013) 285-295.

[19] Surendra Nath Pandeya, Sivakumar Smitha, Mayank Jyoti, Seshaiah Krishnan Sridhar, Acta Pharmaceutica 55 (2005) 27-46.

[20] W. C. Sumpter, Chemical Review (1944) 393-425.

[21] M. Zhu, Journal of Chemical and Engineering Data 46 (2001) 175-176.

[22] A. Apelblat, E. Manzurola, Journal of Chemical Thermodynamics 31 (1999) 85-91.

[23] R. R. Krug, W. G. Hunter, R. A. Grieger, Journal of Physical Chemistry 80 (1976) 2341-2351.

[24] P. S. Kalsi, Organic reactions and their mechanisms-2nd edition; New age international (P) Limited: New Delhi, 2004, 119.

[25] A. A. El-Bindary, A. Z. El-Sonbati, E. H. El-Mosalamy, R. M. Ahmed, Chemistry Papers 57 (2003) 255-258.

[26] Ratnamala P. Sonawane, Rahul R. Tripathi, International Letters of Chemistry, Physics and Astronomy 7(1) (2013) 30-36. 